Article

\title{
Interannual Variations in Growing-Season NDVI and Its Correlation with Climate Variables in the Southwestern Karst Region of China
}

\section{Wenjuan Hou ${ }^{1,2}$, Jiangbo Gao ${ }^{1, *}$, Shaohong $W u^{1}$ and Erfu Dai ${ }^{1}$}

1 Key Laboratory of Land Surface Pattern and Simulation, Institute of Geographic Sciences and Natural Resources Research, Chinese Academy of Sciences, 11A Datun Rd., Beijing 100101, China; E-Mails: houwj.13b@igsnrr.ac.cn (W.H.); wush@igsnrr.ac.cn (S.W.); daief@igsnrr.ac.cn (E.D.)

2 University of Chinese Academy of Sciences, Beijing 100049, China

* Author to whom correspondence should be addressed; E-Mail: gaojiangbo@igsnrr.ac.cn; Tel.: +86-10-6488-9692; Fax: +86-10-6485-1844.

Academic Editors: Alfredo R. Huete and Prasad S. Thenkabail

Received: 14 June 2015 / Accepted: 25 August 2015 /Published: 28 August 2015

\begin{abstract}
In this study, the updated Global Inventory Modeling and Mapping Studies (GIMMS) Normalized Difference Vegetation Index (NDVI) dataset for growing season (April to October), which can better reflect the vegetation vigor, was used to investigate the interannual variations in NDVI and its relationship with climatic factors, in order to preliminarily understand the climate impact on vegetation and provide theoretical basis for the response of ecosystem to climate change. Multivariate linear regression models, including the Ordinary Least Squares (OLS) and Geographically Weighted Regression (GWR), were adopted to analyze the correlation between NDVI and climatic factors (temperature and precipitation) together. Average growing-season NDVI significantly increased at a rate of 0.0015/year from 1982 to 2013, larger than several regions in China. On the whole, its relationship with temperature is positive and also stronger than precipitation, which indicated that temperature may be a limiting factor for the vegetation growth in the Karst region. Moreover, the correlation coefficients between grassland NDVI and climatic factors are the largest. Under the background of NDVI increasing trend from 1982 to 2013, the period of 2009-2012 was chosen to investigate the influencing factors of a sharp decline in NDVI. It can be found that the reduced temperature and solar radiation, caused by the increase in cloud cover and precipitation, may play important roles in the
\end{abstract}


vegetation cover change. All in all, the systematic research on the interannual variations of growing-season NDVI and its relationship with climate revealed the heterogeneity and variability in the complicated climate change in the Karst ecosystem for the study area. It is the Karst characteristics that hinder obtaining more representative conclusions and tendencies in this region. Hence, more attention should be paid to promoting Karst research in the future.

Keywords: growing-season NDVI; interannual variations; NDVI-climate relationship; southwestern Karst region of China

\section{Introduction}

Global climate change and terrestrial ecosystem (GCTE) response is one of the most important and complex issues in the research field of global change [1,2]. Vegetation, as an essential component of the terrestrial ecosystem and the principal part of the soil-vegetation-atmosphere continuum [3], has proved to be sensitive to climate change. Investigation on the correlation between vegetation variation and climate change is the basis for the studies on the sensitivity and vulnerability of the ecosystem to climate change (i.e., the responding processes), and thus provides helpful information for climate change adaption. Therefore, variation in vegetation and its relationship with climatic factors have become the central issues in global change research [4,5]. NDVI (Normalized Difference Vegetation Index), as an effective indicator to monitor vegetation and natural environment at regional and global scales, has been widely used in the research on vegetation activity [6,7], to investigate the impact of climate change on the vegetation growth and ecosystem structure and functions in Eurasia [8-12]. For example, due to global warming [13,14], NDVI presents a tendency to increase not only at the global scale [15], but also in northwestern China [16], western China [17], and the Tibetan Plateau [18]. However, in the arid and semi-arid region (e.g., Mongolian Plateau, Qinghai-Tibet Plateau), the impact of precipitation on NDVI is more significant than that of temperature [19-21]. In a word, the effect of climate change on vegetation cover is complicated because of the spatio-temporal variation in climate change and eco-environmental conditions among different regions.

The southwestern Karst region of China, famous for the largest continuous Karst landform in the world [22], was selected as the study area for the significant sensitivity of its ecosystem to external disturbances, including human activity and climate change [23]. Due to the high population pressure and the vulnerable Karst ecosystem, the contrast between human and environment is stark, causing rock desertification in the Karst region of China. Vegetation plays important roles in the processes of rocky desertification containment and ecological restoration [24,25]. Most previous studies focused on the ecological effects of land use/cover change, mainly at basin scales [26,27]. However, little research was conducted to monitor the long-term vegetation dynamics in the Karst region of China and its spatio-temporal correlation with climatic factors.

This paper aims to explore the interannual variations of growing-season NDVI in the study area, and further identify the relationship between NDVI and climate variables at both temporal and spatial scales. To be specific, this paper will: (1) describe the interannual variations of growing-season NDVI during 
the past three decades and its spatial heterogeneity in the study area, combining methods of Ordinary Linear Squares (OLS) and Mann-Kendall analysis; and (2) apply both the OLS and Geographically Weighted Regression (GWR) to detect the relationship between NDVI and climatic factors.

\section{Study Area}

The southwestern Karst region of China at $101^{\circ} 73^{\prime}-112^{\circ} 44^{\prime} \mathrm{E}$ and $21^{\circ} 26^{\prime}-29^{\circ} 25^{\prime} \mathrm{N}$ (Figure 1), is located in the subtropical/tropical monsoon climate zone with annual precipitation of above $900 \mathrm{~mm}$ [28]. The total area of this region is approximately $5.5 \times 10^{6} \mathrm{~km}^{2}$, including Guangxi Zhuang Autonomous Region (GX), Guizhou Province (GZ), and the eastern part of Yunnan Province (YN). Due to the typical topographical features with widely distributed mountains, there is a great difference in temperature and precipitation among the Karst region.

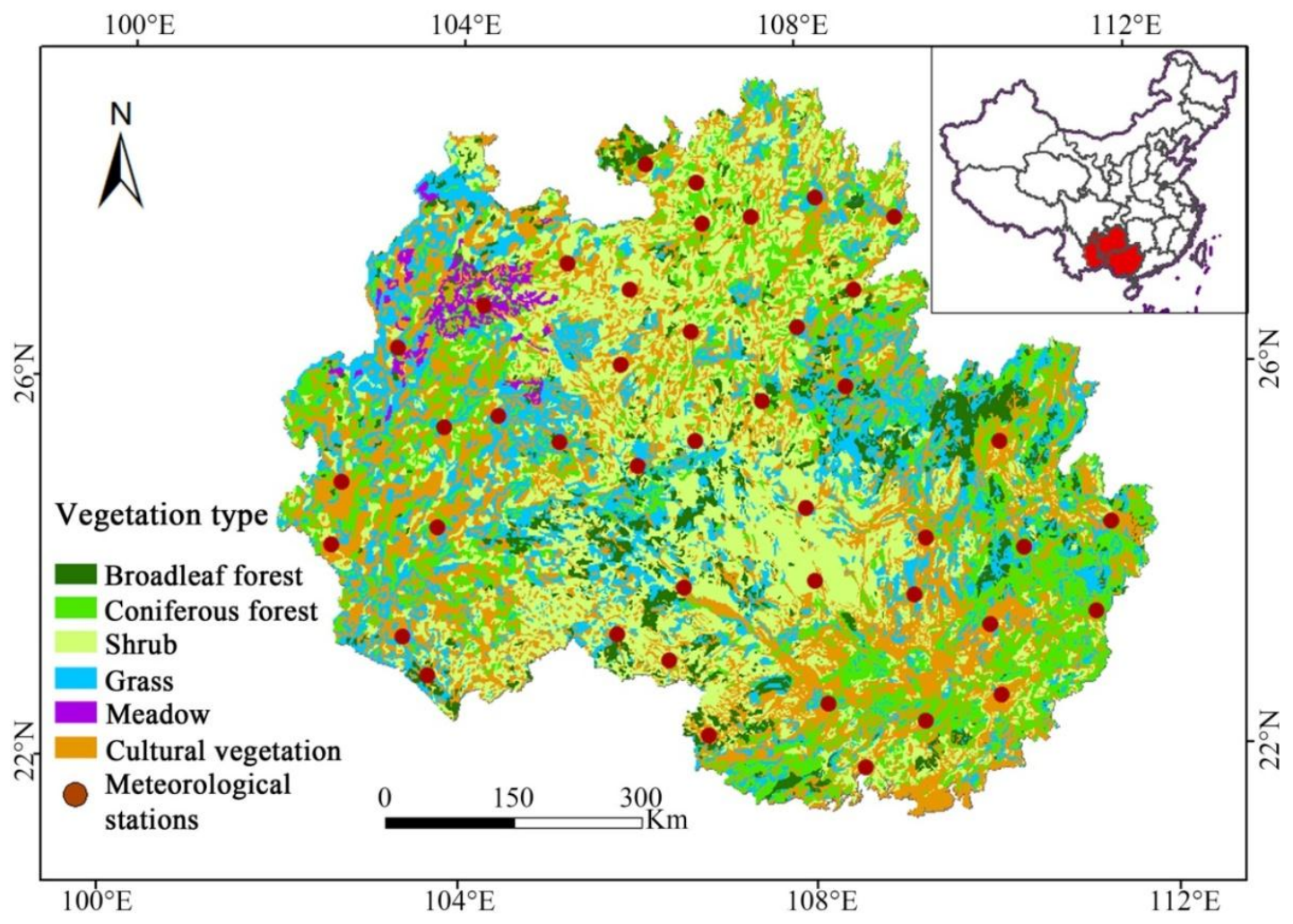

Figure 1. Location of the study area, and spatial distribution of vegetation types and meteorological stations in southwestern China.

According to the vegetation classification map (Figure 1), there are six vegetation types (i.e., broadleaf forest, coniferous forest, shrub, grass, meadow and cultural vegetation). Compared with other types, shrub covers the largest area. Cultural vegetation was mainly located in the industrial and economic development zones, and meadow was mostly located in the northeast part of Yunnan Province. In the areas with Karst landform distribution, unsuitable land use and climate change usually cause vegetation degradation and soil loss [29]. 


\section{Materials and Methods}

\subsection{Data}

\subsubsection{Normalized Difference Vegetation Index (NDVI) Dataset}

The NDVI can accurately reflect the vegetation cover, growth status, biomass and photosynthetic intensity [30,31]. In this study, the third-generation GIMMS (Global Inventory Monitoring and Modeling studies) NDVI from 1982 to 2013 was selected. This dataset, with the spatial resolution of $8 \mathrm{~km}$ and 15-day interval, was produced by the Global Inventory Monitoring and Modeling studies (GIMMS) group [32]. GIMMS NDVI dataset, with the longest time record and its high quality, was used to monitor long-term trends in vegetation activity from regional to global scales [33-35].

Growing-season NDVI, which is defined as the average NDVI from April to October, can better reflect the growth status of vegetation [36,37]. The maximum value composite (MVC) method [38], which can reduce the impacts of atmospheric clouds, shadows, solar zenith angle and aerosol scattering [5], was used to obtain the monthly NDVI of the study area, and then the values from April to October were averaged to create the growing-season NDVI for the years of 1982-2013.

\subsubsection{Meteorological Data}

Monthly precipitation and air temperature datasets during the period of 1982-2013 for the study area were collected from the Chinese meteorological data service [39], which provides records of daily temperatures, vapor pressure, relative humidity, wind speed, precipitation and evaporation rate. There are 43 weather stations located in the study area (Figure 1).Based on the DEM data (derived from United States Geological Survey), the original meteorological data was interpolated to keep the same spatial resolution of $8 \mathrm{~km}$ with NDVI dataset using the AUSPLINE (an interpolation program), and then the meteorological data in the growing season was extracted by the MATLAB 8.1 (R2013a, MathWorks of USA), which can be used for further spatial analyses by the ArcGIS 10.1 software (2012, ESRI).

\subsection{Methods}

\subsubsection{Trend Analysis and Mann-Kendall Test}

The Ordinary Least Squares (OLS), based on the least error sum of squares between predicted and observed values, is of reference value for trend analysis of long-term data [18,40]; however, it does not effectively deal with outliers. Thus, to make sure the results are more convincing, the Mann-Kendall test was adopted to further validate the varying trend and its significance.

(1) Trend Analysis

The unitary linear regression can be used to estimate the NDVI trend at pixel scale according to the Ordinary Least Squares (OLS). In this study, the ArcGIS 10.1 software was used to calculate and show the slope of NDVI from 1982 to 2013. The trend formula is: 


$$
\theta_{\text {slope }}=\frac{n \times \sum_{i=1}^{n} i \times N D V I_{i}-\sum_{i=1}^{n} i \sum_{i=1}^{n} N D V I_{i}}{n \times \sum_{i=1}^{n} i^{2}-\left(\sum_{i=1}^{n} i\right)^{2}}
$$

where: $n$ is the sequence number of monitoring years, from 1 to $32 . N D V I_{i}$ is the growing-season NDVI for the specific year. $\theta_{\text {slope }}$ is the slope of the linear regression, which represents the trend of NDVI during the period. When $\theta_{\text {slope }}>0$, the average NDVI for growing-season from 1982-2013 is increased, and vice versa.

(2) Mann-Kendall Test

Mann-Kendall analysis was first developed by Mann and Kendall, which is a non-parametric, rank-based method for evaluating trends in time-series data [41,42]. Compared to other analysis methods, the use of nonparametric techniques is known to be more resilient to outliers [43]. After a series of improvements, the current calculation process in this study was perfected [44]. To perform this test, you first construct a rank sequence $\left(S_{k}\right)$ for time series:

$$
S_{k}=\sum_{i=1}^{k} r_{i} \quad(k=2,3, \ldots, \mathrm{n})
$$

where $k$ is the dataset record length, here is the year. In addition, $r_{i}$ is:

$$
r_{i}=\left\{\begin{array}{ll}
1 & x_{i}>x_{j} \\
0 & x_{i} \leq x_{j}
\end{array}\right\} \quad(j=1,2, \ldots, i)
$$

Under the assumption of random and independent time series, the statistic $Z$ is defined:

$$
Z_{k}=\frac{\left[S_{k}-E\left(S_{k}\right)\right]}{\sqrt{\operatorname{Var}\left(S_{k}\right)}}(k=1,2, \ldots, \mathrm{n})
$$

Moreover, $\mathrm{Z}_{1}=0, E\left(S_{k}\right)$ and $\operatorname{Var}\left(S_{k}\right)$ is the mathematical expectation and variance, respectively:

$$
\begin{gathered}
E\left(S_{k}\right)=\frac{n(n-1)}{4} \\
\operatorname{Var}\left(S_{k}\right)=\frac{n(n-1)(2 n+5)}{72}
\end{gathered}
$$

That the value of $Z_{k}$ is positive means an increasing trend, and vice versa. Compared $Z_{k}$ with $Z_{\alpha}(\alpha$ is the significance level, $\alpha=0.05$ for this study), the result of $\left|Z_{k}\right|>Z_{\alpha}\left(Z_{0.05}=1.96\right)$ represents that the series has a significant trend during this period.

This trend analysis and significance testing is also applied to the meteorology data, which can be implemented by Raster calculator in ArcGIS and writing a piece of code in MATLAB.

\subsubsection{Multivariate Regression Analysis}

In order to completely and deeply understand the relationship between NDVI and climate, we conducted multivariate regression analysis by Ordinary Linear Squares (OLS) for the temporal scale and Geographically Weighted Regression (GWR) for the spatial scale. 
(1) Ordinary Linear Square

To analyze the correlation between NDVI and climate factors, including temperature and precipitation, we adopted the multivariate linear regression using MATLAB 8.1. The multivariate linear model was established for each pixel:

$$
N D V I=b_{0}+b_{1} \times \text { Temperature }+b_{2} \times \text { Precipitation }+\varepsilon
$$

where $N D V I$ is the growing-season value. $b_{0}$ is the intercept of regression model. $b_{1}$ and $b_{2}$ are the regression coefficients for temperature and precipitation, respectively. $\varepsilon$ is the regression residual.

Through this method, we can obtain the relationship between NDVI and temperature, precipitation, with $b_{1}$ and $b_{2}$. Furthermore, due to the significantly different range between precipitation and temperature, the normalization was conducted to compare the importance of these two climate factors to NDVI variation. After the normalization, the larger absolute value of regression slope means more significant impact of the corresponding independent variable on NDVI [45].

$$
b_{i}^{\prime}=b_{i} \times \sqrt{\frac{\sum_{t=1}^{n}\left(x_{t}-\bar{x}\right)}{\sum_{t=1}^{n}\left(y_{t}-\bar{y}\right)}}
$$

where $b_{i}{ }^{\prime}$ is the standard regression coefficient. $b_{i}$ is the original regression coefficient. $n$ is the sequence number of monitoring years, from 1 to $32 . x$ is the independent variable, for temperature and precipitation. $y$ is the dependent variable, for NDVI. $\bar{x}$ is the average value of $x, \bar{y}$ is the average value of $y$.

(2) Geographically Weighted Regression (GWR)

GWR is an extension of traditional regression techniques such as OLS because it obtains local rather than global parameter estimates [46], thereby addressing the issue of a spatial non-stationary process in which the parameter estimates are functions of location, and as such, vary over space [47].

The GWR model is run for an observation point, using a spatial kernel that centers on the point, and weights observations subject to a distance decay function. The model is expressed as:

$$
y_{i}=\beta_{0}\left(\mu_{i}, v_{i}\right)+\sum_{k=1}^{p} \beta_{k}\left(\mu_{i}, v_{i}\right) x_{i k}+\varepsilon_{i}
$$

where: $\left(\mu_{i}, v_{i}\right)$ denote the coordinate location of the $i$ th point, $k$ expresses the independent variable number. $y_{i}, x_{i k}, \varepsilon i$, respectively, represent the dependent variable, the independent variables, and the random error term at location $i$. $\beta o\left(\mu_{i}, v_{i}\right)$ is the intercept for location $i$, and $\beta_{k}\left(\mu_{i}, v_{i}\right)$ is the slope coefficient for $x_{k}$ at location $i$.

The parameters are estimated from:

$$
\beta\left(\mu_{i}, v_{i}\right)=\left(X^{T} W\left(\mu_{i}, v_{i}\right) X\right)^{-1} X^{T} W\left(\mu_{i}, v_{i}\right) Y
$$

where $\beta\left(\mu_{i}, v_{i}\right)$ represents the unbiased estimate of the regression coefficient. $W\left(\mu_{i}, v_{i}\right)$ is the weighting matrix which acts to ensure that observation near to the specific point has a bigger weight value, and $X$ and $Y$ are matrices for independent and dependent variables, respectively. 
The weighting function, called the kernel function, can be stated using the exponential distance decay form:

$$
\omega_{i j}=\exp \left(-\frac{d_{i j}^{2}}{b^{2}}\right)
$$

where $\omega_{i j}$ represents the weight of observation $j$ for location $i, d_{i j}$ expresses the Euclidean distance between points $i$ and $j$, and $b$ is the kernel bandwidth. If observation $j$ coincides with $i$, the weight value is one. If the distance is greater than the kernel bandwidth, the weight will be set to zero.

\section{Results and Analysis}

\subsection{Temporal-Spatial Variations in Growing-Season NDVI}

The interannual variations in growing-season NDVI for the southwestern Karst region of China are shown in Figure 2. It is indicated that NDVI significantly increased at the rate of $0.0015 /$ year $(r=0.64$, $p=0.0001$ ) from 1982 to 2013 . The variation coefficient is $3.2 \%$, and the maximum appears in the year 2009. Figure $2 \mathrm{~b}$ shows that the NDVI anomaly is mostly negative before the 1994 , but primarily positive after 1994. According to the documentary records, the time series of temperature during 1909-2012, created by Wang and Cao [48,49], shows the level of temperature anomaly relative to 1971-2000 changes from negative to positive, with 1994 as the demarcation point. This may be an important reason for this phenomenon. Moreover, there were a series of drought events during 1985-1993 in southwestern China [50], with the highest frequency and longest time of continuous drought since 1949 [51], which may be another reason for the low level of NVDI before 1994. Generally, vegetation activity cannot be strengthened persistently under the background of climate change. For example, different from the increase tendency of NDVI during the past three decades due to global warming in this study, there is a significant decline from between 2009 and 2012 at a rate of $-0.017 /$ year (Figure 2a). Moreover, the z-score from the Mann-Kendall test (Figure 2c) indicates that NDVI presents an increasing trend in most years with positive z-score values being positive, and, especially for 2004, NDVI showed a significantly rising trend ( $\mathrm{z}$-score $>1.96$ ).

Figure 3 shows the interannual variations in growing-season NDVI for representative vegetation types in this area. In general, the similar rising trend from 1982-2013 can be extracted for these vegetation types (Figure 3, Table 1). Coniferous forest presents the largest increasing rate (0.0016/year, $r=0.64, p=0.0001)$, while meadow has the smallest slope $(0.0008 /$ year, $r=0.23, p=0.1)$. The value ranges were also different between vegetation types; for example, the broadleaf forest fluctuates between 0.7 and 0.8, and most meadow values change between 0.5 and 0.65 (Figure 3) from the annual values of 32 years. Among the six vegetation types, the NDVI value of broadleaf forest, shrub and grassland is beyond the mean level. We also conducted the Mann-Kendall test for NDVI variation of different vegetation types (not shown in the article). The NDVI of cultural vegetation significantly increases from 1998, while the trend of meadow is not stable, and other vegetation types increase significantly around 2005.

As shown in Figure 4a, the mean growing-season NDVI shows obvious spatial heterogeneity, high in the east and low in the west. The NDVI values range from 0.32 to 0.85 . Areas with relatively lower NDVI are mainly distributed in the eastern part of Yunnan Province. Most NDVI values are higher than 0.6 in Guangxi Zhuang Autonomous Region, which means the best vegetation cover. The spatial 
distribution of the NDVI rate presents an overall tendency of increasing from the northwest to southeast (Figure 4b). Uptrend appears in most locations, especially in Guangxi and the eastern part of Guizhou. Comparatively, the rising rate of NDVI in Guangxi Zhuang Autonomous Region is almost higher than $0.001 /$ year, the largest among these three provinces.

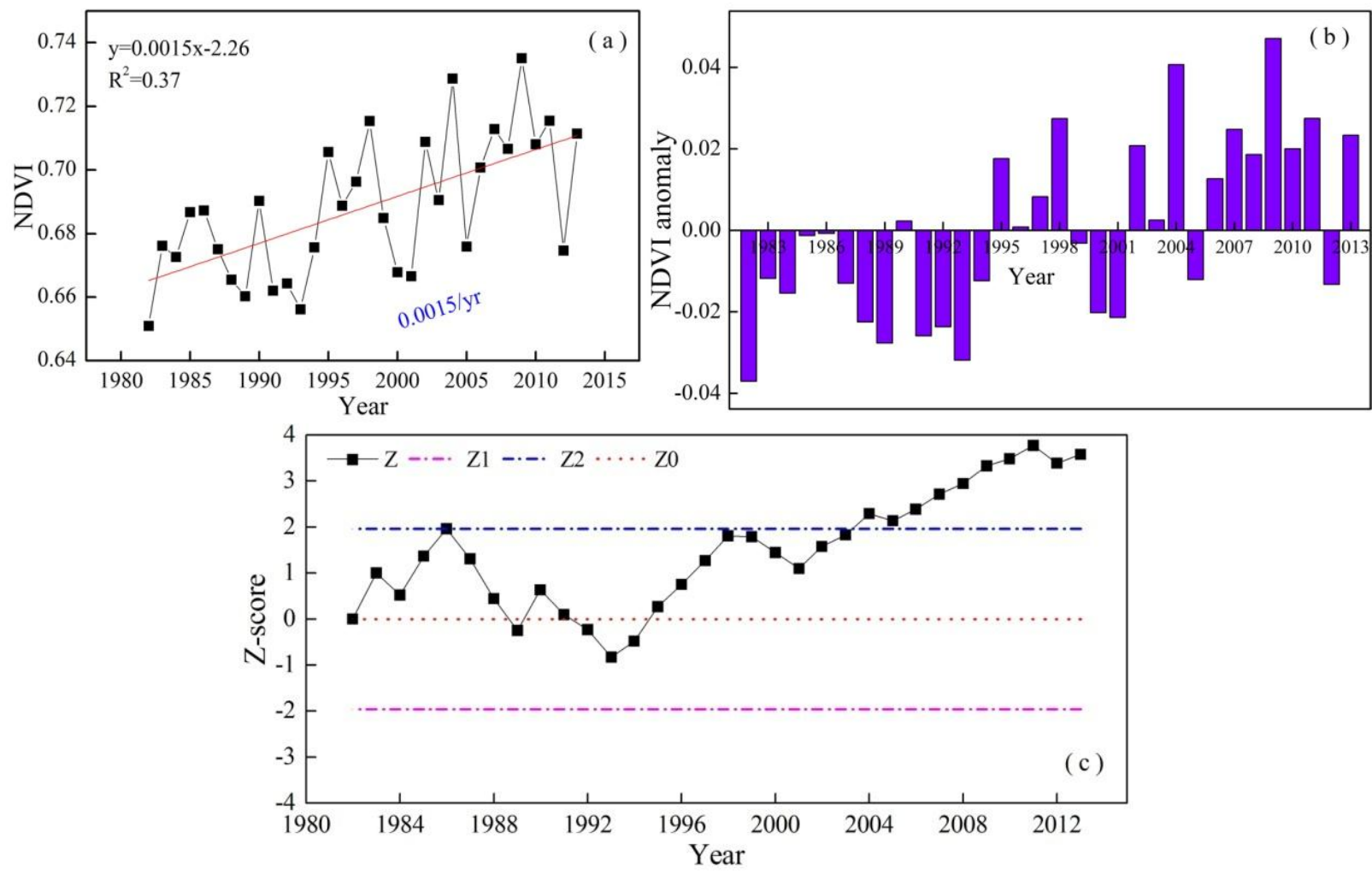

Figure 2. Interannual variations in growing-season NDVI (Normalized Difference Vegetation Index) (a) and NDVI anomaly (b) during 1982-2013in the entire region, using the annual average growing-season NDVI; (c) shows the Mann-Kendall results for trend analysis $(\alpha=0.05, \mathrm{Z} 1=-1.96, \mathrm{Z} 2=1.96)$. The numbers labeled in the figure are the change rate. The NDVI anomaly is based on the average NDVI of the 32 years.
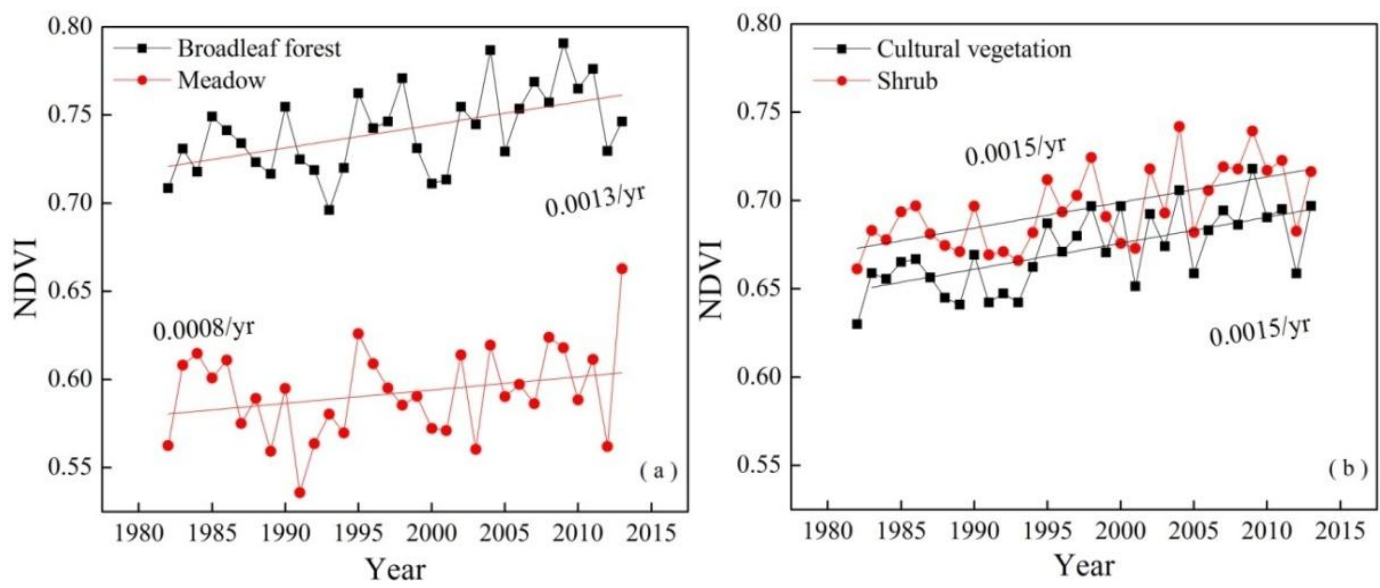

Figure 3. Interannual variations in growing-season NDVI from 1982 to 2013 for the main vegetation types (a, b), using the annual average growing-season NDVI. The numbers labeled in the figure are the change rate of different vegetation types. 
Table 1. Statistical characteristics of growing-season NDVI for different vegetation types during 1982-2013. Average, maximum, and minimum are shown in this table, and the values in the last column are the change rate of NDVI from 1982 to 2013, calculated based on Figure 4a,b. The last two columns are correlation coefficients between NDVI and climatic factors among different vegetation types. The symbol of ** means a 0.01 significance level.

\begin{tabular}{|c|c|c|c|c|c|c|}
\hline \multirow{2}{*}{ Vegetation Type } & \multicolumn{3}{|c|}{ Growing-Season NDVI Value } & \multirow{2}{*}{$\begin{array}{c}\text { NDVI } \\
\text { Rate }\end{array}$} & \multicolumn{2}{|c|}{ Correlation Coefficients } \\
\hline & Average & Maximum & Minimum & & Temperature & Precipitation \\
\hline Broadleaf forest & 0.7412 & 0.8501 & 0.5056 & 0.0013 & $0.315 * *$ & $0.173 * *$ \\
\hline Shrub & 0.6952 & 0.8369 & 0.4866 & 0.0015 & $0.149 * *$ & $0.130 * *$ \\
\hline Grassland & 0.6946 & 0.8405 & 0.4126 & 0.0013 & $0.493 * *$ & $0.289 * *$ \\
\hline Coniferous forest & 0.6871 & 0.8270 & 0.3932 & 0.0016 & $0.252 * *$ & 0.063 \\
\hline $\begin{array}{c}\text { Cultural } \\
\text { vegetation }\end{array}$ & 0.6706 & 0.8398 & 0.3576 & 0.0015 & $0.374 * *$ & $0.182 * *$ \\
\hline Meadow & 0.5910 & 0.7319 & 0.4741 & 0.0008 & $0.412 * *$ & -0.109 \\
\hline
\end{tabular}
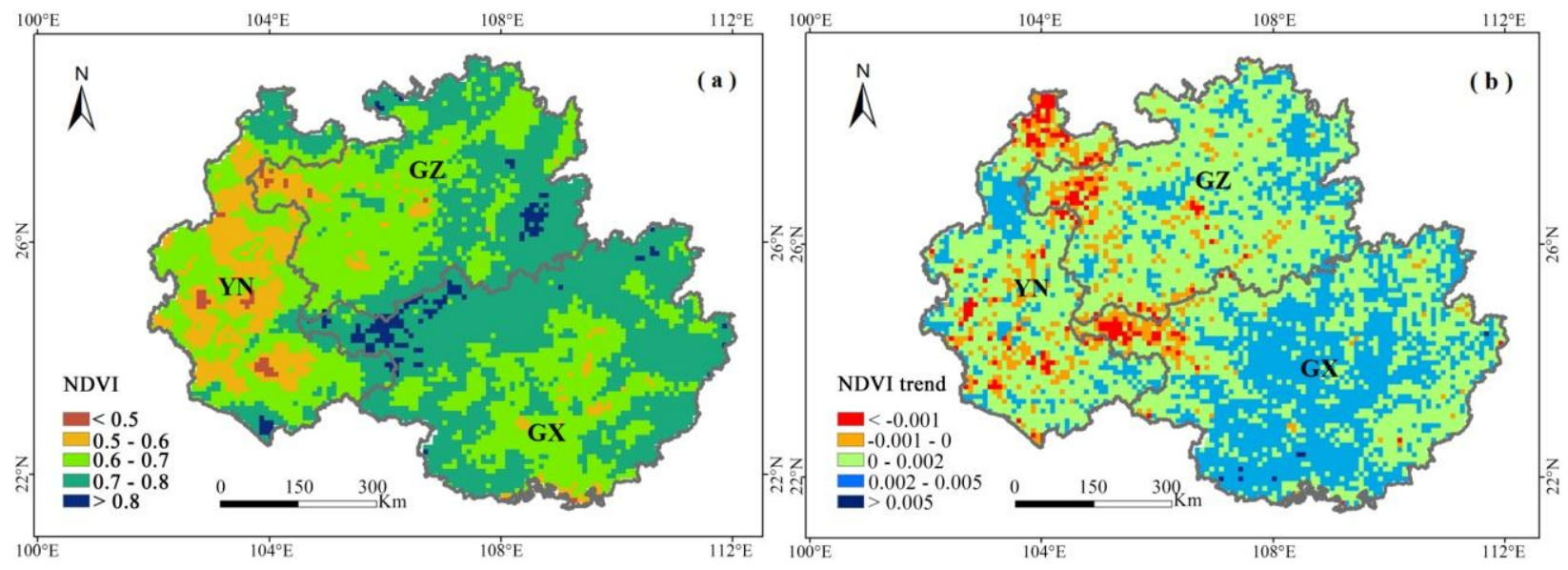

Figure 4. Spatial patterns of average values (a) and temporal trend (b) in growing-season NDVI during 1982-2013.

\subsection{Relationship between NDVI and Climate Variables}

\subsubsection{Interannual Variations in Temperature and Precipitation}

The average growing-season temperature gradually increases at a rate of $0.018^{\circ} \mathrm{C} /$ year (Figure 5a).The temperature anomaly is different each year (Figure 5a), and the fluctuation range is between $-0.6 \sim 0.8{ }^{\circ} \mathrm{C}$ with the obvious negative anomalies appearing before 1995, which is consistent with the dynamic characteristic of NDVI anomaly. Figure $5 \mathrm{~b}$ shows the variations in monthly temperature, and the temperature is more than $5{ }^{\circ} \mathrm{C}$ all year round, with a maximum temperature $\left(25.2{ }^{\circ} \mathrm{C}\right)$ in July. The overall trend of precipitation is presented in Figure 5c, decreasing at the rate of $-1.21 \mathrm{~mm} /$ year (sum of growing-season, monthly average is $-0.17 \mathrm{~mm} /$ year). Figure $5 \mathrm{~d}$ shows the precipitation anomaly for the years 1982-2013. This curve can be divided into three parts, i.e., 1982-1992, 1993-2002, and 2003-2013. The average precipitation for 1993-2002 is higher than the base line, but the other two stages are both in a lower level. The distribution of monthly precipitation is displayed in Figure 5d, which illustrates that the 
rainfall is mainly concentrated in the period of May to August. The Mann-Kendall test was conducted for temperature and precipitation. However, no significant breaking point can be found for this period. Temperature shows an upward trend (z-score $>0$ ) during the whole period, especially increasing from 2008 (z-score > 1.96). Precipitation shows an unstable tendency, approximately decreasing (z-score < 0 ) before 1996, and an increasing trend (z-score > 0) after 1996. Moreover, there is a significant downward trend during 1989-1992, which is consistent with the historical drought event during 1985-1993 [51].
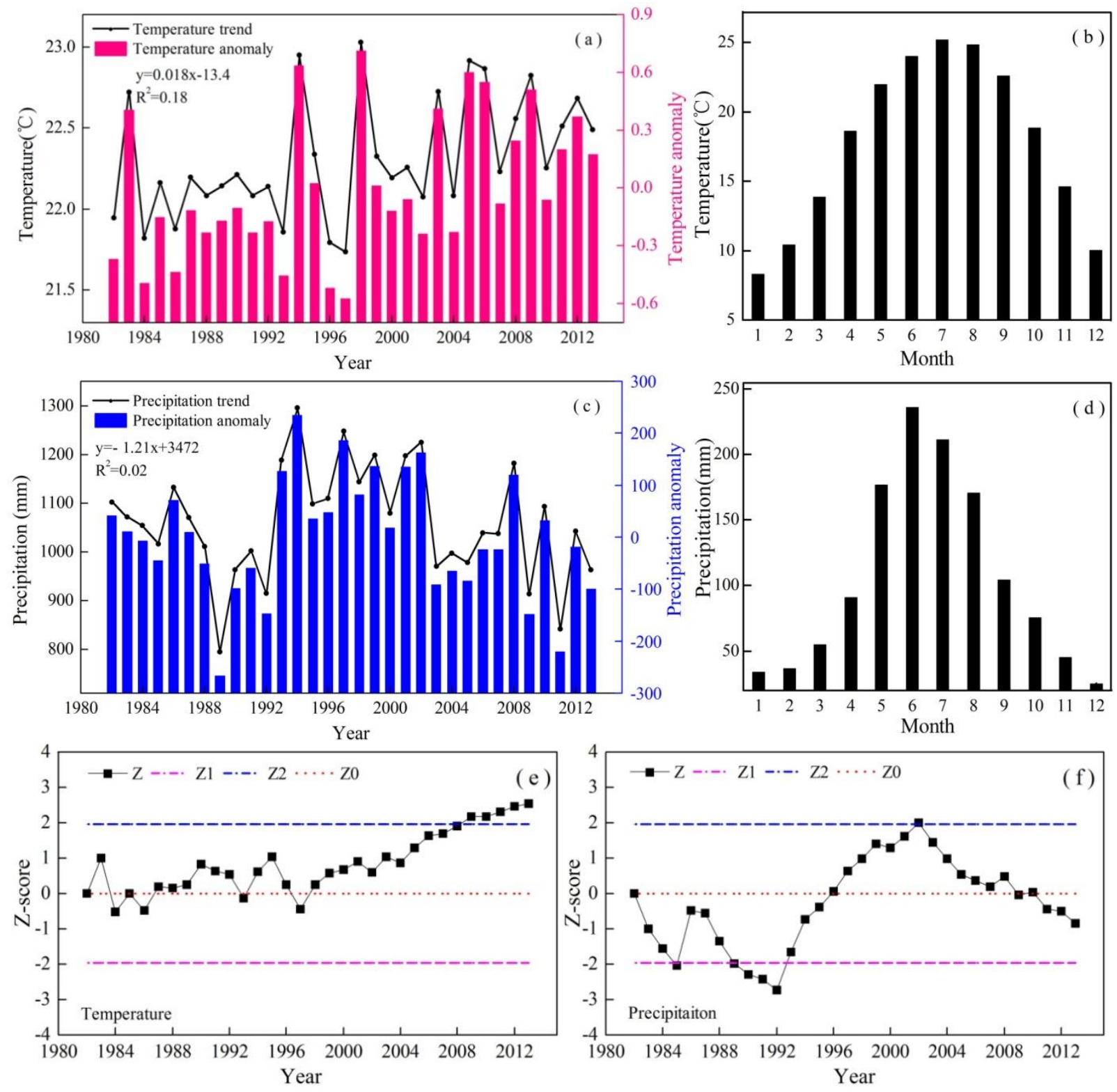

Figure 5. Interannual variations in average growing-season temperature trend and anomaly (a); monthly temperature (b); precipitation trend and anomaly (c); monthly precipitation (d); and the results (e,f) of Mann-Kendall test during 1982-2013 in the entire region. Annual growing-season temperature is the monthly average from April to October, and precipitation is the sum of growing season. The anomaly is also based on the average of 32 years. 


\subsubsection{OLS Analysis for Temporal Relationship}

Based on the datasets of growing-season NDVI, mean temperature and total precipitation for 43 stations with 32 year time series, Figure 6a shows that NDVI increases with temperature rise in a certain range, while the relationship between NDVI and precipitation is weak. The overall coefficients for precipitation are lower than temperature (Figure 6), which means that the impact of precipitation on NDVI is weaker than that from temperature. The reason why the impact of precipitation on NDVI is relatively weak can be explained by the rich precipitation in the study area and the binary hydrological structure of the Karst region, rendering the rainfall unable to be utilized effectively. Furthermore, the overall relationship between NDVI and climatic factors among different vegetation types was detected (shown in Table 1). It is indicated that the correlation coefficients between grassland NDVI and climatic factors are the largest, followed by broadleaf forest and cultural vegetation. Specifically, the relationship between the NDVI of meadow and temperature is positive, but negative with precipitation, which is different from other types.
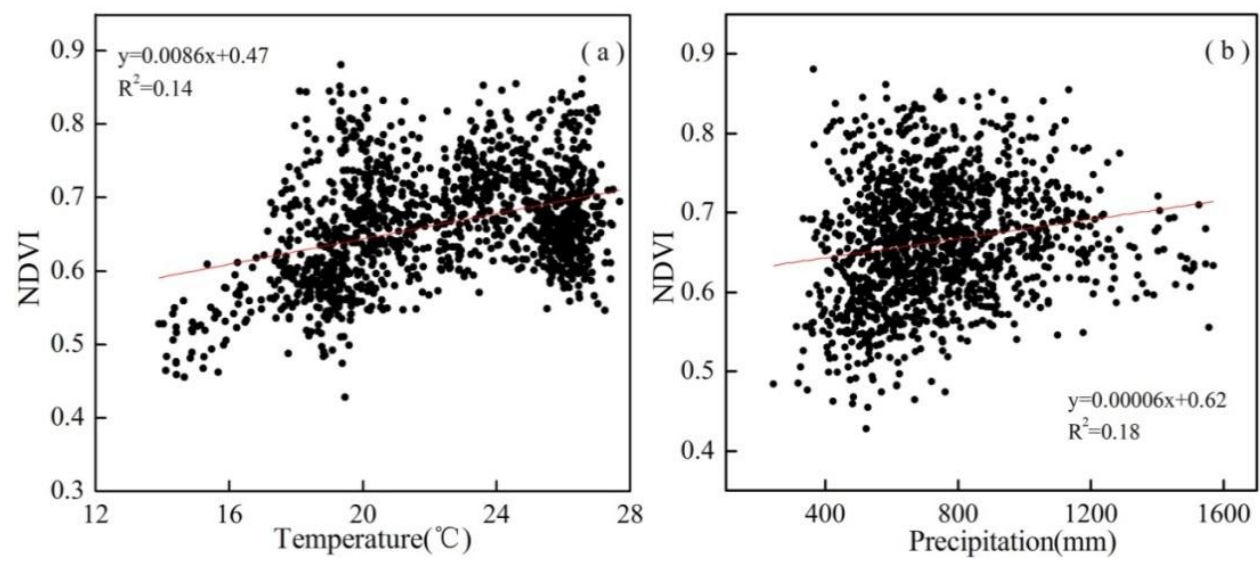

Figure 6. The overall relationship between annual growing-season NDVI and temperature (a); precipitation (b) during 1982-2013. These three sets of data are the annual average for growing-season NDVI, temperature and accumulated precipitation of 32 years for 43 stations.

The multivariate regression analysis method was used to examine the spatially heterogeneous influence of climate change on NDVI. The higher the absolute value of standardized regression coefficients, the greater the impact on NDVI. Figure 7 shows the spatial patterns of multi-regression coefficients between NDVI and temperature and precipitation. Figure 7a indicates that NDVI was positively correlated with temperature in about $70 \%$ of the entire region, because the canopy photosynthesis and vegetation activities can be strengthened by temperature rising [52]. The areas with coefficients larger than 0.4 and smaller than -0.4 only account for $11 \%$ of the study area, and mainly scatter over the northern and western parts. Most of the region covered by broadleaf forest and shrub has relatively low absolute value of regression coefficients. The growing-season NDVI increases as temperature rises within an appropriate range. However, high temperature beyond the suitable range will result in negative impact on vegetation. 

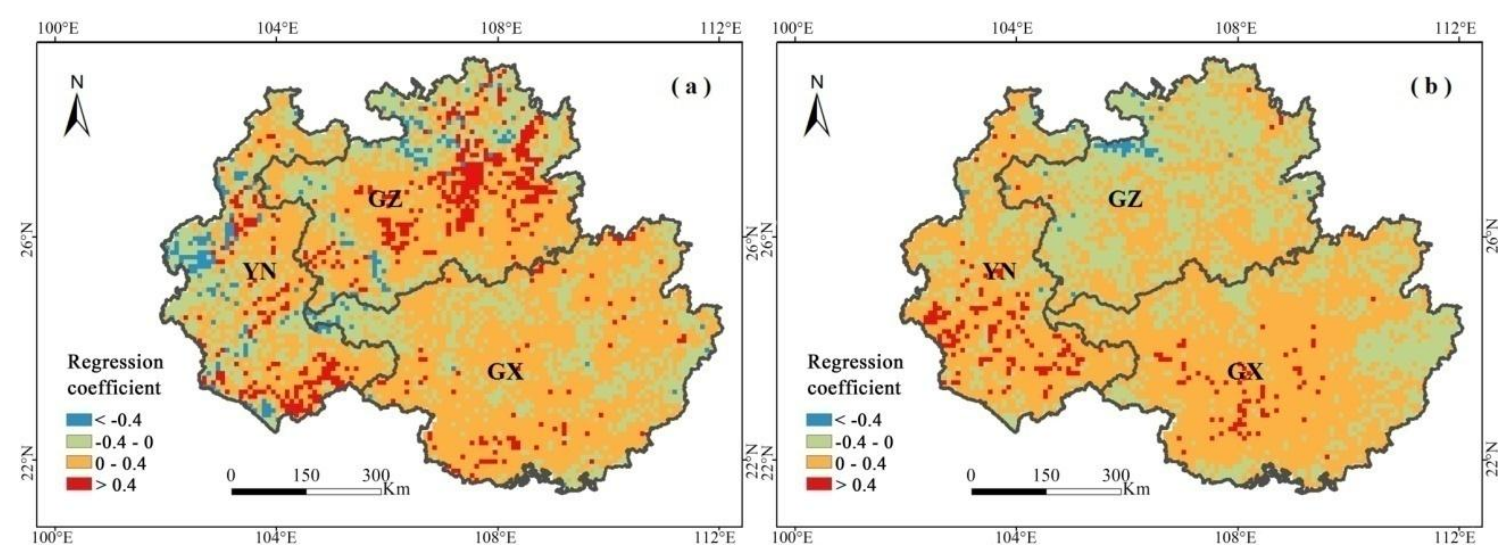

Figure 7. Multivariate regression coefficients of temperature (a); and precipitation (b) to NDVI based on pixel during 1982-2013.

The spatial pattern of regression coefficient for precipitation is shown in Figure 7b. In general, the NDVI was positively correlated with precipitation in most areas, but a negative correlation mainly appears in the northern part. The area of precipitation coefficient in the range of $>0.4$ and $<-0.4$ only accounts for $4 \%$, mostly in the southern and northwestern corner of the study region. The determination coefficient presents the model performance. The values of $\mathrm{R}^{2}$ for all grids in this region are located in the range of $0-0.56$. As a whole, $\mathrm{R}^{2}$ in $99.5 \%$ of the region is less than 0.4 , with high $\mathrm{R}^{2}$ in the west and low in the east (not shown in the article).

\subsubsection{GWR Analysis for Spatial Relationships}

To better understand the spatial relationship between NDVI and climatic variables, we also conducted a GWR analysis. Moreover, combining those two methods can compensate for the shortcomings of OLS. The static and dynamic relationships between NDVI and climatic factors are both explored by GWR. The static regression applied the 32-year average of annual growing-season NDVI as dependent variables with average temperature and precipitation as independent variables. The dynamic regression was conducted with the varying rate of NDVI (Figure 4b) as dependent variables, and correspondingly with variations of temperature and precipitation as independent variables. GWR analysis can be done in ArcGIS 10.1; the regression results are shown in Figure 8. The coefficient surfaces with colors ranging from blue to red represent values from low to high. Additionally, the dots with different sizes overlain in the surfaces are standard errors; these values measure the reliability of each coefficient estimate.

The results in Figure 8a, bare the static regression between average NDVI and climatic factors. The relationship between multi-year average NDVI and temperature is positive, with an obvious spatial variance, low in the southeast and high in the northwest. Figure $8 \mathrm{~b}$ shows that the relationship between NDVI and precipitation is either positive or negative, and the positive correlation is mainly distributed in Yunnan Province. Figure 8c,d shows the coefficients of dynamic regression. It is evident that the relationship between variations in NDVI and temperature is negative, gradually weakening from the east to west. The change range is from -0.0073 to -0.00005 . However, the regression coefficients between the trend of NDVI and precipitation are positive, with a smaller change range $(0.0003-0.0004)$ than for temperature. These results also indicate that NDVI is more sensitive to temperature, which is consistent with the above OLS analysis. 

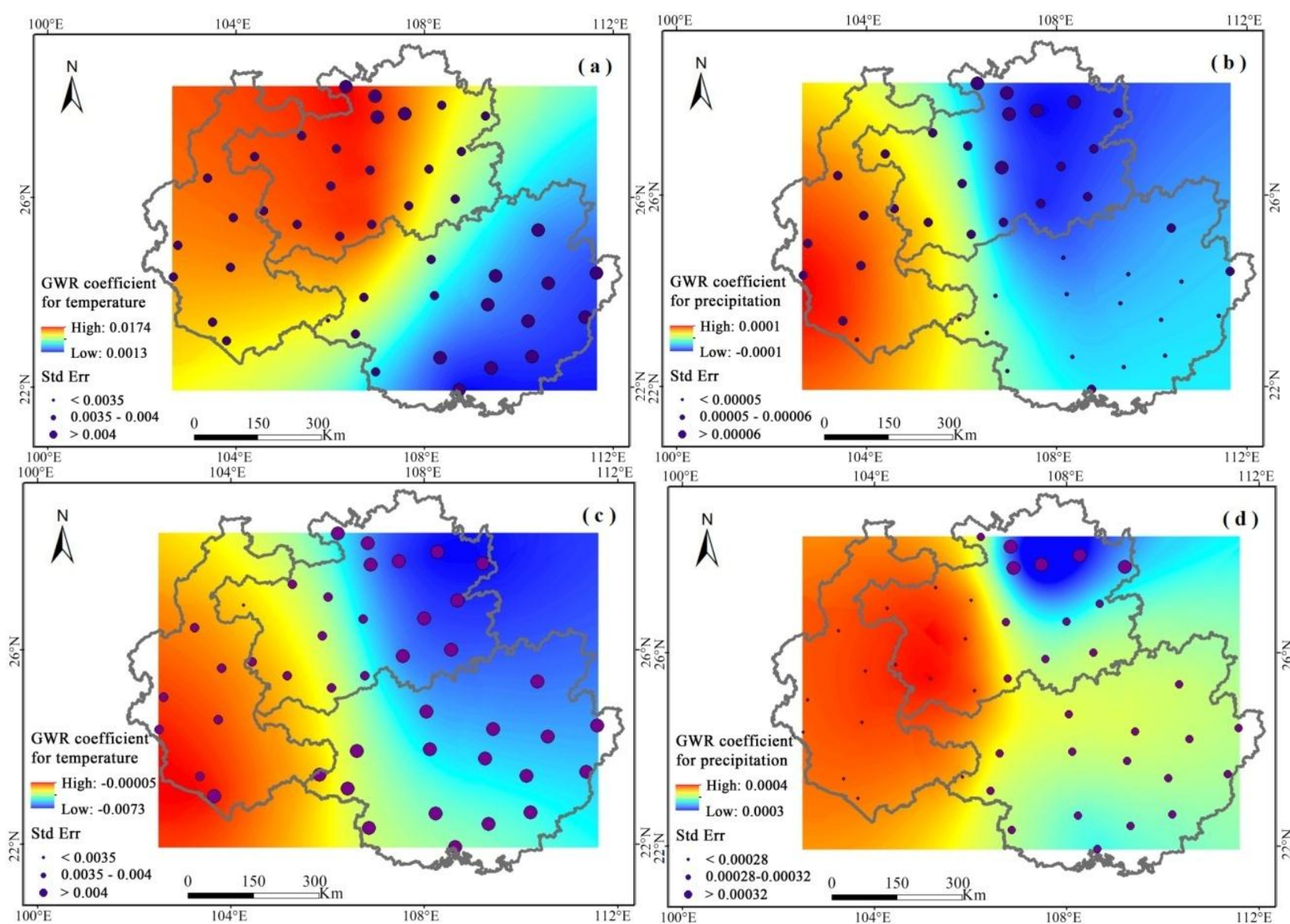

Figure 8. Geographically Weighted Regression analysis between NDVI and temperature and precipitation during 1982-2013. (a) coefficients image for temperature; (b) coefficients image for precipitation; (c) coefficients image for temperature trend; (d) coefficients image for precipitation trend. Figure 8a,b are static regression, and Figure 8c,d are dynamic regression. Std Err measures the reliability of each coefficient estimate.

\subsection{Variation Characteristics in NDVI during 2009-2012 and Its Correlation with Climate Variables}

As was pointed out previously, the NDVI variation presents a significant uptrend during the whole period, but sharply decreasing processes also exist. For example, there is a significant decrease for NDVI after the year of 2009 , with an overall rate of $-0.017 /$ year. In contrast to the above analysis on the impact of climate change on the NDVI uptrend, in this section, the variation characteristics from 2009 to 2012 and its possible reasons will be explored.

The spatial pattern of growing-season NDVI variations during 2009-2012 is shown in Figure 9. Figure 9 indicates the variation characteristics of great decline in most areas, especially in Guizhou Province, with the decreasing range at less than -0.02/year. Especially in 2012, a significant decrease appears in most of the region; the NDVI anomaly in the northern part of the study area is less than -0.05 . Figure 10 shows the relationships between NDVI and climate variables based on the multivariate regression model simulation. Figure 10a indicates that the influence of temperature on NDVI in most areas is positive, especially in the central part of the study area, which means that NDVI decreases with the temperature dropping. Statistical results also show that the regression coefficients larger than 0.4 occupy $52 \%$ of the entire region, covered by shrub and broadleaf forest. Figure 10b shows the spatial 
distribution of regression coefficients for precipitation. It turns out that the impact of precipitation change on NDVI is mainly negative over most of the region. The coefficients less than -0.4 occupy $39 \%$ of the region.

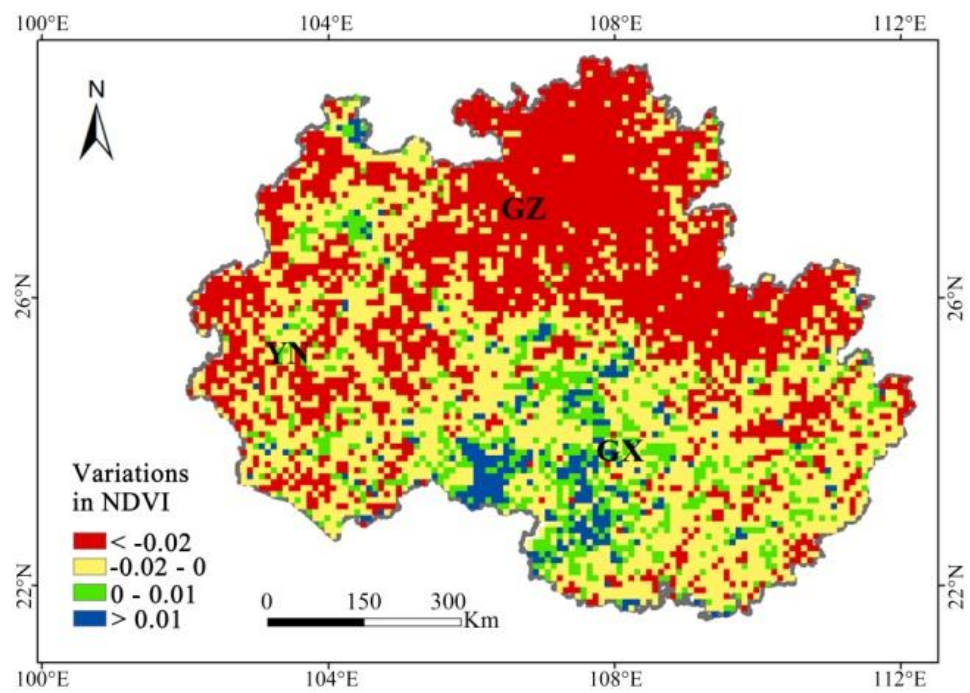

Figure 9. Spatial patterns of variations in growing-season NDVI during 2009-2012.

The positive impact of temperature and negative impact of precipitation may be attributed to the increase in cloud cover and rainfall, which could lead to the decrease in solar radiation and temperature [53,54], and further impede photosynthesis. The static and dynamic relationships from the GWR analysis between NDVI and climatic factors during 2009-2012 are also explored (data not shown), which illustrate similar results as the above: NDVI declines with a decrease in temperature mainly in the western and northern parts. In conclusion, the influence of temperature on vegetation is more significant than precipitation.
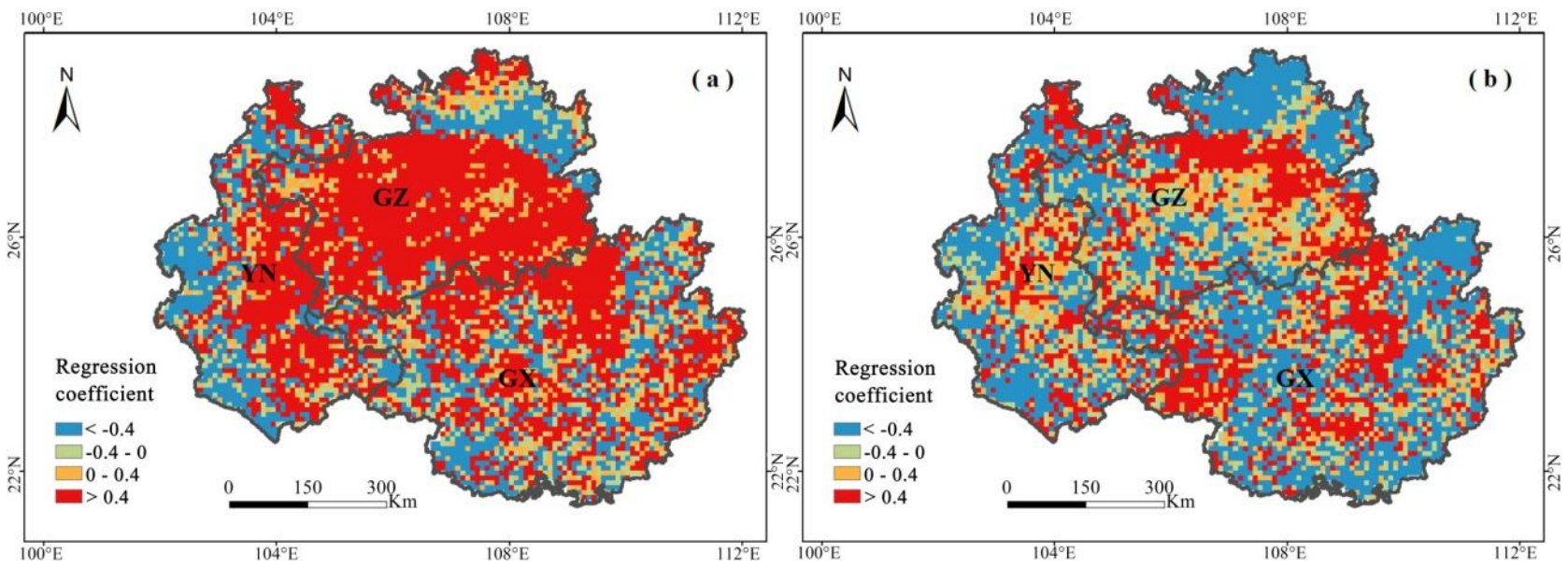

Figure 10. Multivariate regression coefficients of temperature (a); and precipitation (b) to NDVI based on pixel during 2009-2012. 


\section{Discussion}

The distribution of regression coefficients between NDVI and climate factors presents the characteristic of spatial heterogeneity. This is not only because of the spatial variation in climate change, but also due to the complicated and heterogeneous Karst habitat [55,56], which may create some uncertainties of influences on vegetation. The unsuitable land use and a series of ecological restoration projects from the 1990s may also attribute to the heterogeneous distribution of regression slopes. Furthermore, the relationship between NDVI and precipitation is weaker than for temperature, which is different from the arid and semi-arid region (e.g., Mongolian Plateau, Qinghai-Tibet Plateau) [19-21]. On the one hand, this may be because the study area is located in the subtropical monsoon climate zone, with rich precipitation and suitable temperature, so the slight changes in rainfall will not heavily affect vegetation growth. On the other hand, the binary hydrological structure of the Karst region leads to the huge drain of rainfall [57], which suggests that precipitation cannot be effectively used for vegetation growth. As for the decline in NDVI during 2009-2012, especially in Guizhou Province, the positive correlation with temperature and the negative correlation with precipitation of NDVI may indicate that the increase in cloud cover and precipitation causes the reduced temperature and solar radiation [53,54] that subsequently weaken photosynthesis and thus hinder vegetation activities.

Compared with conclusions from other areas, the responses of vegetation cover (0.0015/year) to climate change $\left(0.018{ }^{\circ} \mathrm{C} /\right.$ year for temperature, and $0.17 \mathrm{~mm} /$ year for precipitation, a monthly average of the growing-season) in the Karst region are more sensitive during 1982-2013. For example, the NDVI increase rate in northwest China is $0.0005 /$ year with temperature rate of $0.067{ }^{\circ} \mathrm{C} /$ year and precipitation rate of $0.815 \mathrm{~mm} /$ year [16]. The NDVI changing rate in the Mongolian Plateau is $-0.0009 /$ year during 1994-2010, with temperature $-0.047^{\circ} \mathrm{C} /$ year and precipitation $-4.0233 \mathrm{~mm} /$ year [58]. The NDVI change rate in the Koshi River basin of the Tibetan Plateau is also smaller than that of the Karst region [59].

Finally, the systematic research on the interannual variations in growing-season NDVI and its relationship with climate reveals the heterogeneity and variability in the complicated climate change in the study area and in the Karst ecosystem, which hinders the attainment of more representative conclusions and the ability to surmise general rules about this region. Our findings do not only help with understanding the impact of climate change on vegetation, but also provide a theoretical basis for climate change adaption and ecosystem restoration in a degraded region. For example, climate effect should be considered in the process of restoration and reconstruction in the future, including several engineering measures of resisting high temperature, enhancing utilization efficiency of rainfall and so on. Therefore, based on the important scientific and practical significance, more attention should be paid to promote progress of Karst research in the future.

\section{Conclusions}

Vegetation is very sensitive to climate change and human activities. At the local scale, previous studies show that the ecological effects of land use/cover change are significant, especially in the studied area [26,27]. At greater scale, the influence of climate change on the vegetation dynamics is significant and more important $[60,61]$, but the systematic research is needed to enhance the long-term vegetation dynamics and spatio-temporal correlation with climatic factors in the Karst region of China. This 
research focuses on the temporal-spatial variation of growing-season NDVI and its relationship with climate variables in the southwestern Karst region of China during the 1982-2013 period. The main conclusions are as follows:

Average growing-season NDVI significantly increased from 1982 to 2013 at a rate of $0.0015 /$ year ( $r=0.64, p=0.0001$ ), but with no sudden change. The increase rate of coniferous forest is the largest (0.0016/year) of the six vegetation types. Spatially, there is significant heterogeneity in the distribution of growing-season NDVI with lower values in the western part and higher values in the east. On the whole, its relationship with climatic factors indicated that temperature may be a limiting factor for the vegetation growth in the Karst region. The spatial patterns of multivariate regression coefficients also show a high degree of heterogeneity, and the positive relationship with temperature covers about $70 \%$ of the entire region. As for non-stationary relationships between average NDVI and temperature, static GWR analysis shows a positive relationship and gradually increases from the southeast to northwest. The absolute coefficient values of dynamic GWR for climatic factors are both high in the east and low in the west. In conclusion, the influence of temperature on vegetation is more significant than precipitation.

During 2009-2012, an obvious decline process of NDVI appears, and the decline range in Guizhou Province is the largest ( $<-0.02 /$ year). In 2012, there is the lowest NDVI value. The relationship between NDVI and temperature in most areas is positive, with the regression coefficients larger than 0.4 occupying $52 \%$ of the entire region, which means that NDVI decreases with a temperature drop (impedes photosynthesis). However, the impact of precipitation change on NDVI is mainly negative, with coefficients less than -0.4 occupying $39 \%$ of the region. The negative impact may be attributed to the increase in cloud cover and rainfall, which could lead to the decrease in solar radiation and temperature, and further impede photosynthesis. The static and dynamic relationships from GWR analysis show similar results to the above. In conclusion, the influence of temperature on vegetation is more significant than precipitation.

\section{Acknowledgments}

This work was supported by the National Basic Research Program of China (Grant No. 2015CB452702), the National Natural Science Foundation of China (Grant No. 41301089), the National Science and Technology Support Program of China (Grant No. 2012BAC19B10, Grant No. 2013BAC04B02). The authors wish to thank the NASA Global Inventory Modeling and Mapping Studies (GIMMS) group for producing and sharing the AVHRR GIMMS NDVI3g dataset. We appreciate the helpful comments of Linghui Guo from Henan Polytechnic University, Dongsheng Zhao, Yunhe Yin and Shuai Hou from Institute of Geographic Sciences and Natural Resources Research, Chinese Academy of Sciences. We also thank the journal editor and the anonymous reviewers for their useful comments and great efforts on this paper.

\section{Author Contributions}

All authors contributed significantly to this manuscript. To be specific, Shaohong Wu, Jiangbo Gao and Wenjuan Hou designed this study. Wenjuan Hou and Jiangbo Gao were responsible for the data processing, analysis, and paper writing. Last but not least, Shaohong Wu and Erfu Dai made very valuable suggestions for this paper. 


\section{Conflicts of Interest}

The authors declare no conflict of interest.

\section{References}

1. Walker, B.; Steffen, W. IGBP Science No.1: A Synthesis of GCTE and Related Research. Available online: http://www.igbp.net/download/18.1b8ae20512db692f2a680007651/1376383135 146/science-1.pdf (accessed on 14 June 2015).

2. Parmesan, C.; Yohe, G. A globally coherent fingerprint of climate change impacts across natural systems. Nature 2003, 421, 37-42.

3. Sun, H.Y.; Wang, C.Y.; Niu, Z.; Li, B. Analysis of the vegetation cover change and the relationship between NDVI and environmental factors by using NOAA time series data. J. Remote Sens. 1998, 2, 204-210. (In Chinese)

4. Piao, S.L.; Cui, M.D.; Chen, A.P.; Wang, X.H.; Ciais, P.; Liu, J.; Tang, Y.H. Altitude and temperature dependence of change in the spring vegetation green-up date from 1982 to 2006 in the Qinghai-Xizang Plateau. Agric. For. Meteorol. 2011, 151, 1599-1608.

5. Piao, S.L.; Wang, X.H.; Ciais, P.; Zhu, B.; Wang, T.; Liu, J. Changes in satellite-derived vegetation growth trend in temperate and boreal Eurasia from 1982 to 2006. Global Chang. Biol. 2011, 17, 3228-3239.

6. Beck, P.S.A.; Atzberger, C.; Hogda, K.A. Improved monitoring of vegetation dynamics at very high latitudes, a new method using MODIS NDVI. Remote Sens. Environ. 2006, 100, 321-336.

7. Mao, D.H.; Wang, Z.M.; Song, K.S.; Liu, D.W.; Zhang, B.; Zhang, S.M.; Luo, L.; Zhang, C.H. The vegetation NDVI variation and its responses to climate change and LUCC from 1982 to 2006 year in northeast permafrost region. Chin. Environ. Sci. 2010, 31, 283-292.

8. Zhang, X.X.; Ge, Q.S.; Zheng, J.Y. Impacts and lags of global warming on vegetation in Beijing for the last 50 years based on remotely sensed data and phonological information. Chin. J. Ecol. 2005, 24, 123-130. (In Chinese)

9. Xin, Z.B.; Xu, J.X.; Zheng, W. The impact of climate change and human activities on vegetation coverage in the Loess Plateau. Sci. China Ser. D Earth Sci. 2007, 37, 1504-1514.

10. Brookshire, E.N.J.; Weaver, T. Long-term decline in grassland productivity driven by increasing dryness. Nat. Commun. 2015, 6, doi:10.1038/ncomms8148.

11. Zhao, M.; Running, S.W. Drought-induced reduction in global terrestrial net primary production from 2000 through 2009. Science 2010, 329, 940-943.

12. Park, H.S.; Sohn, B. Recent trends in changes of vegetation over East Asia coupled with temperature and rainfall variations. J. Geophys. Res. 2010, 115, doi:10.1029/2009JD012752.

13. Qin, D.H.; Plattner, G.K.; Tignor, M.; Allen, S.K.; Boschung, J.; Nauels, A.; Xia, Y.; Bex, V.; Midgley, P.M; et al. Climate Change 2013: The Physical Science Basis; Cambridge University Press: Cambridge, UK; New York, NY, USA, 2013.

14. Piao, S.L.; Ciais, P.; Huang, Y.; Shen, Z.H.; Peng, S.S.; Li, J.S.; Zhou, L.P., Liu, H.Y.; Ma, Y.C.; Ding, Y.H.; et al. The impacts of climate change on water resources and agriculture in China. Nature 2010, 467, 43-51. 
15. Eastman, J.; Sangermano, F.; Machado, E.; Rogan, J.; Anyamba, A. Global trends in seasonality of Normalized Difference Vegetation Index (NDVI), 1982-2011. Remote Sens. 2013, 5, 4799-4818.

16. Dai, S.P.; Zhang, B.; Wang, H.J.; Wang, Y.M.; Guo, L.X.; Wang, X.N.; Li, D. Vegetation cover change and the driving factors over northwest China. J. Arid Land 2011, 3, 25-33.

17. Meng, M.; Ni, J.; Zong, M. Impacts of changes in climate variability on regional vegetation in China: NDVI-based analysis from 1982 to 2000. Ecol. Res. 2011, 26, 421-428.

18. Sun, J.; Cheng, G.; Li, W.; Sha, Y.; Yang, Y. On the variation of NDVI with the principal climatic elements in the Tibetan Plateau. Remote Sens. 2013, 5, 1894-1911.

19. Guo, B.; Zhou, Y.; Wang, S.X.; Tao, H.P. The relationship between NDVI and climate factors in the semi-arid region: A case study in Yalu Tsangpo River basin of Qinghai-Tibet Plateau. J. Mt. Sci. 2014, $11,926-940$.

20. Zhou, X.Y.; Shi, H.D.; Wang, X.R. Impact of climate change and human activities on vegetation coverage in the Mongolian Plateau. Arid Zone Res. 2014, 31, 604-610. (In Chinese)

21. Wang, Z.S.; Huang, M.; Yan, H.M.; Wang, J.B.; Yue, X.L. Spatiotemporal variations of vegetation and climate impacts on it in Ghana from 1982-2006. J. Geo. Inform. Sci. 2015, 17, 78-85. (In Chinese)

22. Cai, H.Y.; Yang, X.H.; Wang, K.J.; Xiao, L.L. Is forest restoration in the southwest China Karst promoted mainly by climate change or human-induced factors? Remote Sens. 2014, 6, 9895-9910.

23. Yuan, D.X. World correlation of Karst ecosystem: Objectives and implementation plan. Adv. Earth Sci. 2001, 16, 461-466. (In Chinese)

24. Cai, Y.L.; Meng, J.J. Ecological reconstruction of degraded land: A social approach. Sci. Geogr. Sin. 1999, 19, 198-204. (In Chinese)

25. Huang, Q.H.; Cai, Y.L. Spatial pattern of Karst rock desertification in the middle of Guizhou province, southwestern China. Environ. Geol. 2006, 52, 1325-1330.

26. Peng, J.; Cai, Y.L.; He, G.; Wang, W.B.; Huang, Q.H.; Yan, F. Land use/cover change in ecologically fragile Karst areas: A case study in Maotiaohe river basin, Guizhou, China. J. Mt. Sci. 2007, 25, 566-576. (In Chinese)

27. Yang, Q.Q.; Wang, K.L.; Zhang, C.H.; Yue, Y.M.; Tian, R.C.; Fan, F.D. Spatio-temporal evolution of rocky desertification and its driving forces in Karst areas of northwestern Guangxi, China. Environ. Earth Sci. 2011, 64, 383-393.

28. Liu, J.; Tan, X.; Wan, J.; Ma, J.; Zhang, N. Comparative analysis between the 2010 severe drought in southwest China and typical drought disasters. Chin. Water Resour. 2011, 9, 17-20.

29. Wang, W.; Wang, W.J.; Li, J.S.; Wu, H.; Xu, C.; Liu, T. The impact of sustained drought on vegetation ecosystem in southwest China based on remote sensing. Procedia Environ. Sci. 2010, 2 , 1679-1691.

30. Sellers, P.J.; Meeson, B.W.; Hall, F.G.; Asrar, G.; Murphy, R.E.; Schiffer, R.A.; Bretherton, F.P.; Dickinson, R.E.; Ellingson, R.G.; Field, C.B. Remote sensing of the land surface for studies of global change: Models-Algorithms-Experiments. Remote Sens. Environ. 1995, 51, 3-26.

31. Fang, J.Y.; Piao, S.L.; Tang, Z.Y.; Peng, C.H.; Ji, W. Interannual variability in net primary productivity and precipitation. Science 2001, 293, 1723. 
32. Tucker, C.J.; Pinzon, J.E.; Brown, M.E.; Slayback, D.A.; Pak, E.W.; Mahoney, R.; Vermote, E.F.; el Saleous, N. An extended AVHRR 8-km NDVI dataset compatible with MODIS and SPOT vegetation NDVI data. Int. J. Remote Sens. 2005, 26, 4485-4498.

33. Mao, D.H.; Wang, Z.M.; Luo, L.; Ren, C.Y. Integrating AVHRR and MODIS data to monitor NDVI changes and their relationships with climatic parameters in northeast China. Int. J. Appl. Earth Obs. Geoinf. 2012, 18, 528-536.

34. Wang, J.; Meng, J.J.; Cai, Y.L. Assessing vegetation dynamics impacted climate change in the southwestern Karst region of China with AVHRR NDVI and AVHRR NPP time-series. Environ. Geol. 2008, 54, 1185-1195.

35. Li, H.X.; Wei, X.H.; Zhou H.Y. Rain-use efficiency and NDVI-based assessment of Karst ecosystem degradation or recovery: A case study in Guangxi, China. Environ. Earth Sci. 2014, doi:10.1007/s12665-014-3679-6.

36. Chen, H.L. Variations of Vegetation Cover and Its Impact on Climate and Water Source in Huanghe-Huaihe-Haihe Zone; Chinese Academy of Meteorological Sciences: Beijing, China, 2007. (In Chinese)

37. Piao, S.L.; Mohammat, A.; Fang, J.Y.; Cai, Q.; Feng, J. NDVI-based increase in growth of temperate grasslands and its responses to climate changes in China. Glob. Environ. Chang. 2006, $16,340-348$.

38. Holben, B.N. Characteristics of maximum-value composite images from temporal AVHRR data. Int. J. Remote Sens. 1986, 7:11, 1417-1434.

39. China Meteorological Data Sharing Service System. The Monthly Surface Meteorological Dataset of China. Available online: http://cdc.nmic.cn/dataSetLogger.do?changeFlag=dataLogger\& tpCat=SURF\&titleName=\%E5\%9C\%B0\%E9\%9D\%A2\%E6\%B0\%94\%E8\%B1\%A1\%E8\%B5\% 84\%E6\%96\%99 (accessed on 11 April 2015).

40. Chen, F.J.; Shen, Y.J.; Hu, Q.L.; Qi, Y.Q.; Zhang, Y.C. Responses of NDVI to climate change in the Hai Basin. J. Remote Sens. 2011, 15, 401-414.

41. Mann, H.B. Nonparametric tests against trend. Econometrica 1945, 13, 245-259.

42. Kendall, M.G. Rank Correlation Methods; Hafner: New York, NY, USA, 1962.

43. Lanzante, J.R. Resistant, robust and non-parametric techniques for the analysis of climate data: Theory and examples, including applications to historical radiosonde station data. Int. J. Climatol. 1996, 16, 1197-1226.

44. Wei, F.Y. Modern Statistic Diagnosing and Predicting Techniques of Climate; China Meteorological Press: Beijing, China, 1999. (In Chinese)

45. Chen, Y.; Li, B.G.; Liu, G.; Zhan, Z.G. System Analysis of Resources and Environment; Beijing Normal University Press: Beijing, China, 2009; pp. 20-24. (In Chinese)

46. Fotherigham, A.S.; Brusdon, C.; Charlton, M. Geographically Weighted Regression: The Analysis of Spatially Varying Relationships; John Wiley \& Sons: West Sussex, UK, 2002.

47. Li, Z.; Huffman, T.; McConkey, B.; Townley-Smith, L. Monitoring and modeling spatial and temporal patterns of grassland dynamics using time-series MODIS NDVI with climate and stocking data. Remote Sens. Environ. 2013, 138, 232-244.

48. Wang, S.W.; Ye, J.L.; Gong, D.Y.; Zhu, J.H.; Yao, T.D. Construction of mean annual temperature series for the last one hundred years in China. Q. J. Appl. Meteorol. 1998, 9, 392-401. (In Chinese) 
49. Cao, L.J.; Zhao, P.; Yan, Z.W.; Jones, P.; Zhu, Y.N.; Yu, Y.; Tang G.L. Instrumental temperature series in eastern and central China back to the nineteenth century. J. Geophys. Res. Atmos. 2013, 118, 8197-8207.

50. Zhang, S.F.; Su, Y.S.; Song, D.D.; Zhang, Y.Y.; Song, H.Z.; Gu, Y. The Historical Drought of China; Hehai University Press: Nanjing, China, 2008; pp. 111-666. (In Chinese)

51. Liu, J.G.; Wan, J.H.; Tan, X.M.; Ma, J.M.; Zhang, N.Q. Drought in southwest China from autumn 2009 to spring 2010 and its comparative analysis with historical drought events. J. Disaster Prev. Mitig. Eng. 2011, 31, 196-200. (In Chinese)

52. Fang, J.Y.; Piao, S.L.; He, J.Y. Increasing terrestrial vegetation activity in China, 1982-1999. Sci. Chin. Life Sci. 2004, 47, 229-240.

53. Li, Z.X.; He, Y.Q.; An, W.L.; Song, L.L.; Zhang, W.; Catto, N.; Wang, Y; Wang, S.J.; Liu, H.C.; Cao, W.H.; et al. Climate and glacier change in southwestern China during the past several decades. Environ. Res. Lett. 2011, 6, 45404-45427.

54. Lu, A.G. Precipitation effects on temperature: A case study in China. J. Earth Sci. 2011, 22, 792-798.

55. Liu, F.; Wang, S.J.; Luo, H.B.; Liu, Y.S.; Liu, H.Y. Micro-habitats in Karst forest ecosystem and variability of soils. Acta Pedol. Sin. 2008, 45, 1055-1062. (In Chinese)

56. Liu, C.Q. Biogeochemical Processes and the Surface Material Cycle: The Cycles of Biogenic Elements of Soil-Vegetation System in the Southwestern Karst China; Science Press: Beijing, China, 2009.

57. Du, X.L.; Wang, S.J. Space-time distribution of soil water in a Karst area: A case study of the Wangjiazhai catchment, Qingzhen, Guizhou Province. Earth Environ. 2008, 36, 193-201. (In Chinese)

58. Bao, G.; Qin, Z.H.; Bao, Y.H.; Zhou, Y.; Li, W.J.; Sanjjav, A. NDVI-based long-term vegetation dynamics and its response to climatic change in the Mongolian Plateau. Remote Sens. 2014, 6, 8337-8358.

59. Zhang, Y.L.; Gao, J.G.; Liu, L.S.; Wang, Z.F.; Ding, M.J.; Yang, X.C. NDVI-based vegetation changes and their responses to climate change from 1982 to 2011: A case study in the Koshi River Basin in the middle Himalayas. Glob. Planet. Chang. 2013, 108, 139-148.

60. Peng, S.S.; Piao, S.L.; Ciais, P.; Fang, J.Y.; Wang, X.H. Change in winter snow depth and its impacts on vegetation in China. Glob. Chang. Biol. 2010, 16, 3004-3013.

61. Jiang, D.J.; Zhang, H.; Zhang, Y.; Wang, K. Interannual variability and correlation of vegetation cover and precipitation in Eastern China. Theor. Appl. Climatol. 2014, 118, 93-105.

(C) 2015 by the authors; licensee MDPI, Basel, Switzerland. This article is an open access article distributed under the terms and conditions of the Creative Commons Attribution license (http://creativecommons.org/licenses/by/4.0/). 